\title{
Voltage Sag Mitigation in Utility Distribution System Using STATCOM with Hysteresis Current Controller
}

\author{
Laxmi Lata $^{1}$, Dr.M.K.Elango ${ }^{2}$ \\ PG Student [Power Systems Engineering], Dept. of EEE, K.S.Rangasamy College of Technology, Tiruchengode, \\ Tamilnadu, India ${ }^{1}$ \\ Professor, Dept. of EEE, K.S.Rangasamy College of Technology, Tiruchengode, Tamilnadu, India ${ }^{2}$
}

\begin{abstract}
This paper presents three phase Voltage Source Inverter based STATCOM using Hysteresis current controller for mitigating voltage sag due to sudden increase in load. A STATCOM injects a current to the system such that it negates the effect of nonlinear current waveform generated by load. Three phases Voltage Source Inverter based on MOSFET is designed and firing pulses to the device is given by hysteresis current controller, which produces proper switching frequency to the inverter to manipulate the voltage sag during change in load. Advantage of the proposed method is that it eliminates the need of modulator. This model compensates the voltage sag with efficient and effective manner. Because of its fast dynamic response to any disturbance, the STATCOM offer improved quality of supply by giving an inherently faster response and greater output to a system with depressed voltage. The STATCOM using Hysteresis current controller scheme in distribution system for power quality improvement is simulated using MATLAB/SIMULINK in power system block set. The results produced by this method are validated with the Statcom using space vector modulation technique.
\end{abstract}

KEYWORDS: Power Quality, Static Synchronous Compensator (STATCOM), Voltage sag, Switching Frequency, Hysteresis Current Controller.

\section{I.INTRODUCTION}

Nowadays, Electric utility and customers both require high level of quality of electric power Poor power quality is characterized as voltage sag, voltage swell, harmonic distortion, voltage interruption, transient and surges. Among these, voltage sag is the common. The effects of a sag are often more noticeable than those of a swell. Sag of duration longer than three cycles is often visible in a reduction in the output of lights. Reactive power exchange improves the network stability by increasing the voltage collapse limit [1].Grid codes from the transmission system is introduced for supporting the voltage under grid fault [2].combination of active rectifiers and constant power loads can exchange small amount of reactive power based on their ratings [3].To overcome this problem method of generating the reference signal for UPQC is introduced .It consists of shunt converter mainly for eliminating current harmonics and series converter for compensating voltage sag/voltage swell [4]. To mitigate the voltage sag problem, various methods based on the application of series (DVR) and parallel (DSTATCOM) custom power devices are discussed in [5]. In order to support the grid voltage during voltage sag distributed generation system is very important [6]. For power quality improvement DSTATCOM fed by Photo Voltaic (PV) array are introduced for power quality improvement in distribution system. The Icos $\Phi$ algorithm is introduced here for DSTATCOM [7]. For the application of custom power devices, wide range of controller become came to know among these, the Static Synchronous Compensator based on VSC principle is mostly used.

STATCOM can be used to control power factor, regulate voltage, and stabilize power flow and to improve dynamic performance of power system [8]. For power quality improvement various controllers mainly used in custom power devices are studied in [9-11].Various issues while designing these controllers for STATCOM are studied in [13]. By injecting the negative sequence reactive power, voltage deviation were reduced in [14]. 


\title{
9 \\ ISSN (Print) : $2320-3765$ \\ ISSN (Online): $2278-8875$ \\ International Journal of Advanced Research in Electrical, Electronics and Instrumentation Engineering
}

\author{
(An ISO 3297: 2007 Certified Organization)
}

Vol. 4, Issue 3, March 2015

The objective of this paper is to propose a controller for Statcom during voltage sag that is able to support the grid voltage under voltage sag. Hysteresis current controller doesn't need modulator as it generates the switching frequency by comparing directly the actual current with reference current. By controlling the magnitude and phase angle of the output voltage of the VSC, both active and reactive power can be exchanged between the distribution system and the STATCOM. The device should be installed as close to the sensitive load to maximize the compensating capability. Voltage Source Converter is the main component of the STATCOM .The STATCOM has a function of compensating reactive power, absorbing the harmonics and compensating the voltage sag. This paper is focus on the function of compensating voltage sag.

\section{II.SYSTEM DESCRIPTION AND CONTROL SYSTEM OF STATCOM}

This section describes the general description of STATCOM, and the proposed control system of STATCOM. This system consists of STATCOM connected to the grid in order to compensate voltage sag and control method to produce switching frequency to the inverter.

\section{A. Static Synchronous Compensator (STATCOM)}

In fig 1, it shows the Generating system connected to the load through the Grid. If the load is suddenly increases means current increases and thereby voltage reduces. So we cannot able to give the quality of power to the end user .In order to compensate this problem STATCOM is connected to the grid, thereby it needed the pulses for VSC to inject compensating current. Proper switching frequency is generated by the controller. In this work Hysteresis Current Control is used. Capacitor is connected across the VSC to maintain constant de voltage in order to allow the operation of Voltage Source Converter (VSC).

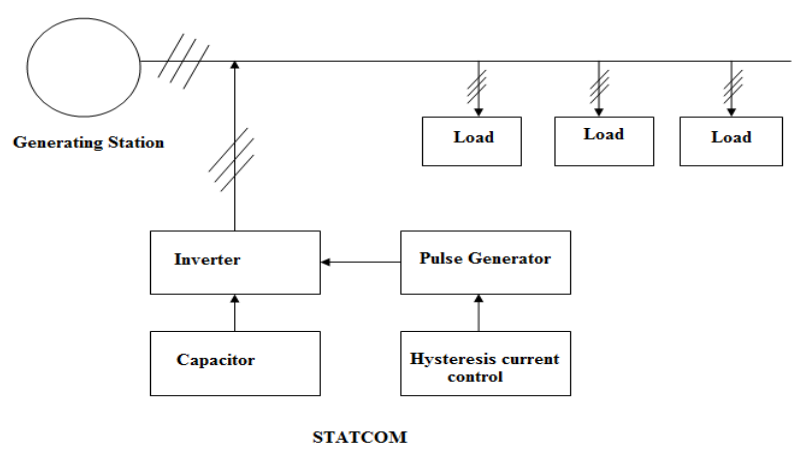

Fig. 1 Diagram of power system with STATCOM

\section{B. Control System of STATCOM}

In fig 2, it shows the block diagram of STATCOM with control system. The voltage at the PCC and the current at the converter side are sensed and given as an input to the control system. This control system produces control input $u$ and having following objectives [1].

1) For compensating power loss it should be ensure that small active power absorption is necessary from the $\mathrm{AC}$ network. This is done by regulating the capacitor voltage $\mathrm{Vdc}$ to the voltage set point $\mathrm{Vdc}{ }^{*}$.

2) Safe operation of STATCOM means the current should not be exceeded. To ensure this, A current set point $\mathrm{I}^{*}$ is employed.

3) The PCC voltage should be maintained between the set point $\mathrm{V}^{*}{ }_{\max }$ and $\mathrm{V}^{*}{ }_{\min }$ 


\section{International Journal of Advanced Research in Electrical, Electronics and Instrumentation Engineering}

(An ISO 3297: 2007 Certified Organization)

Vol. 4, Issue 3, March 2015

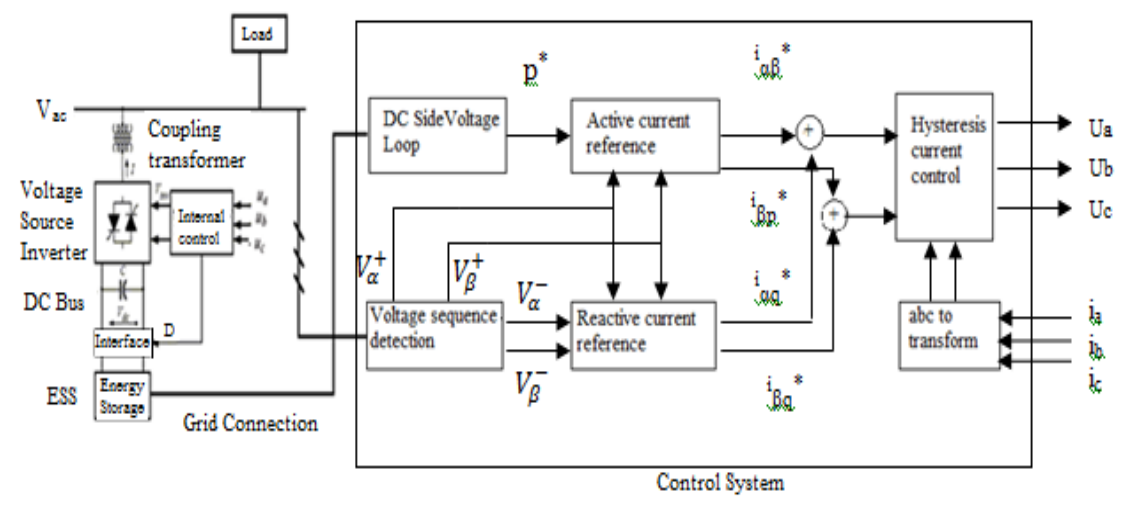

Fig. 2 Control System of STATCOM

The internal loop of a control system is designed to provide fast and accurate current control. The external loop is responsible for generating the current references. The inputs of the controller are the measured phase voltages $\mathrm{v}$ at the Point Of Common Coupling (PCC), the current $i$ and the dc link voltage $V_{d c}$.

Voltage $\mathrm{v}$ and current $\mathrm{i}$ are transformed into Stationary Reference Frame (SRF) values. Voltage $\mathrm{V}_{\alpha}$ and $\mathrm{V}_{\beta}$ are then decomposed into symmetric components using a sequence extractor.

$$
\begin{aligned}
& \mathrm{v}_{\alpha}=\mathrm{v}_{\alpha}^{+}+\mathrm{v}_{\alpha}^{-} \\
& \mathrm{v}_{\beta}=\mathrm{v}_{\beta}^{+}+\mathrm{v}_{\beta}^{-}
\end{aligned}
$$

This symmetric voltage can be defined as

$$
\begin{aligned}
& \mathrm{v}_{\alpha}^{+}=\mathrm{v}^{+} \cos \left(\mathrm{wt}+\varphi^{+}\right) \\
& \mathrm{v}_{\beta}^{+}=\mathrm{v}^{+} \sin \left(\mathrm{wt}+\varphi^{+}\right) \\
& \mathrm{v}_{\alpha}^{-}=\mathrm{v}^{-} \cos \left(-\mathrm{wt}-\varphi^{-}\right) \\
& \mathrm{v}_{\beta}^{-}=\mathrm{v}^{-} \sin \left(-\mathrm{wt}-\varphi^{-}\right)
\end{aligned}
$$

The symmetric sequence extractor is a key aspect to characterize the grid voltage. The dc-link voltage regulator is in charge of the active power reference $\mathrm{P} *$ that keeps power balance. The voltage support block needs first to detect the voltage sag. This can be done by computing the voltage rms in each phase. When one or several rms values drop below a predefined threshold, the voltage support control is activated. The voltage $V_{\alpha}$ and $V_{\beta}$ are given to the reactive current reference to generate reactive current of both the sequence.

$$
\begin{aligned}
& \mathrm{i}_{\alpha \mathrm{q}}^{*}=\frac{2}{3} \frac{\mathrm{k}_{\mathrm{q}} \mathrm{v}_{\beta}^{+}+\left(1-\mathrm{k}_{\mathrm{q}}\right) \mathrm{v}_{\beta}^{-}}{\mathrm{k}_{\mathrm{q}}\left(\mathrm{v}^{+}\right)^{2}+\left(1-\mathrm{k}_{\mathrm{q}}\right)\left(\mathrm{v}^{-}\right)^{2}} \mathrm{Q}^{*} \\
& \mathrm{i}_{\beta \mathrm{q}}^{*}=\frac{2}{3} \frac{-\mathrm{k}_{\mathrm{q}} \mathrm{v}_{\alpha}^{+}-\left(1-\mathrm{k}_{\mathrm{q}}\right) \mathrm{v}_{\alpha}^{-}}{\mathrm{k}_{\mathrm{q}}\left(\mathrm{v}^{+}\right)^{2}+\left(1-\mathrm{k}_{\mathrm{q}}\right)\left(\mathrm{v}^{-}\right)^{2}} \mathrm{Q}^{*}
\end{aligned}
$$




\section{9 \\ ISSN (Print) : $2320-3765$ \\ ISSN (Online): 2278 - 8875 \\ International Journal of Advanced Research in Electrical, Electronics and Instrumentation Engineering}

(An ISO 3297: 2007 Certified Organization)

\section{Vol. 4, Issue 3, March 2015}

Similarly active power reference is given to the active current reference there it compares the power with voltage to generate active current of both the sequence.

$$
\begin{aligned}
& \mathrm{i}_{\alpha \mathrm{p}}^{*}=\frac{2}{3} \frac{\mathrm{v}_{\alpha}^{+}}{\left(\mathrm{v}^{+}\right)^{2}} \mathrm{P}^{*} \\
& \mathrm{i}_{\beta \mathrm{p}}^{*}=\frac{2}{3} \frac{\mathrm{v}_{\beta}^{+}}{\left(\mathrm{v}^{+}\right)^{2}} \mathrm{P}^{*}
\end{aligned}
$$

The active current reference and reactive current reference are the compared to generate the actual current reference for hysteresis current controller. The current references is generated according to the set point $\mathrm{V}^{*}{ }_{\mathrm{dc}}$ and $\mathrm{I}^{*}$.

$$
\begin{aligned}
& \mathrm{i}_{\alpha}^{*}=\mathrm{i}_{\alpha \mathrm{p}}^{*}+\mathrm{i}_{\alpha \mathrm{q}}^{*} \\
& \mathrm{i}_{\beta}^{*}=\mathrm{i}_{\beta \mathrm{p}}^{*}+\mathrm{i}_{\beta \mathrm{q}}^{*}
\end{aligned}
$$

In hysteresis current controller, actual current reference and the current derived from $\mathrm{ABC}$ to $\alpha \beta$ transform are compared to generate the switching signal for inverter, thereby control can be done.

\section{III.REVIEW OF CONVENTIONAL CONTROL STRATEGY}

In fig 3 , it shows the basic block diagram during voltage sag. To compensate voltage sags, the inverter should be injecting the compensating current into the grid. so, first we should know the sequence of voltage coming to the grid .Voltage sequence detector perform this function. These sequences of voltage then given to reference generation block to generate the reference current vector with the use of voltage sequences and the reference power signal that is generated from the DC link voltage controller[15]. Finally the space vector modulation, one of the methods for controlling pulse width modulation is used to derive the control signals for the device.

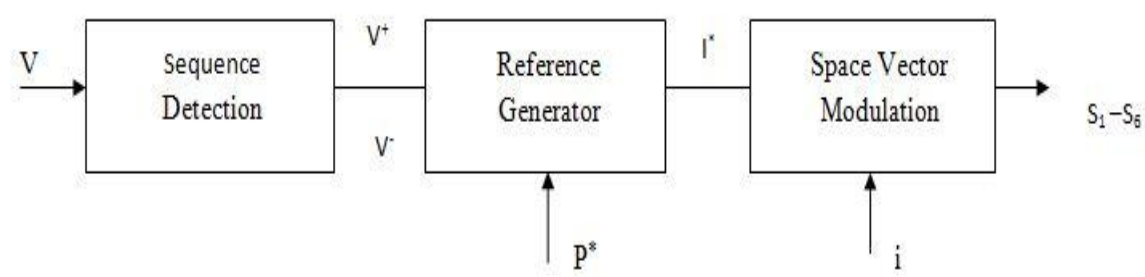

Fig. 3 Control Block Diagram

Space vector modulation is generally used for the control of PWM, and for the creation of AC waveform. Control signal to the device is given in such a way that thyristors on the same leg doesn't turned on otherwise short circuit will happen. In this reference signal is sampled with frequency. Then phase voltage for all of these 8 combinations of switching pattern can be calculated and converted into reference frame. This transformation results six non-zero vector. These non-zero vectors are the original switching states for the device. This control method is somewhat complicated because, for each instant it signals is compared with the frequency band, thereby switching losses must be there. 


\section{9 \\ ISSN (Print) : $2320-3765$ \\ ISSN (Online): 2278 - 8875 \\ International Journal of Advanced Research in Electrical, Electronics and Instrumentation Engineering}

(An ISO 3297: 2007 Certified Organization)

\section{Vol. 4, Issue 3, March 2015}

\section{IV.PROPOSED CONTOL METHOD}

In fig 4 , it shows the structure of hysteresis current controller where $S_{I}, S_{I I}, S_{I I I}, S_{I V}, S_{V}$, $S_{V I}$. These switching signals are generating by comparison of actual current as $i_{a}, i_{b}, i_{c}$ in the respective phase with the reference signal as $i_{a}$, ref, $i_{b}$,ref and $\mathrm{i}_{\mathrm{c}, \text { ref }}$ in the respective phase.

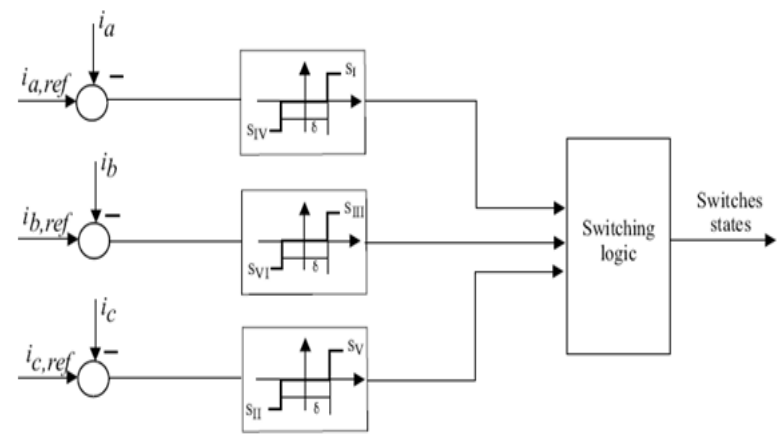

Fig. 4 Structure of Hysteresis Current Controller

In this work hysteresis current controller is implemented in control block of inverter. As explained in above example for the control of heater temperature limit is setting likewise here for mitigating voltage sag, first it should check the voltage thereby lower limit of voltage with tolerance value is setting here. When the voltage is below this value, the STATCOM comes into action and by comparing the voltage difference between the inverter and the PCC, injected current is derived. In the control block, inputs to the inverter are DC capacitor voltage $\mathrm{V}_{\mathrm{dc}}$, reference current is also set, converter side current $I_{g-a b c}$, and initial lower limit of voltage that is essential for starting the process . $V_{\mathrm{dc}}$ is regulated to $\mathrm{Vdc}^{*}$ and by comparing its present and previous value $\mathrm{i}_{\mathrm{d}}{ }^{*}$ current is derived. This is considered as an inverter current. $\mathrm{I}_{\mathrm{g}-}$ abc is converted to dq reference frame thereby deriving $\mathrm{I}_{\mathrm{de}}$ and $\mathrm{I}_{\mathrm{qe}}$ current then comparing $\mathrm{i}_{\mathrm{d}}{ }^{*}$ with $\mathrm{I}_{\mathrm{de}}$ and $\mathrm{i}_{\mathrm{q}}{ }^{*}$ with $\mathrm{I}_{\mathrm{qe}}$, error signals are generating finally by comparing this error signal with actual current thereby switching frequency to the inverter are derived.

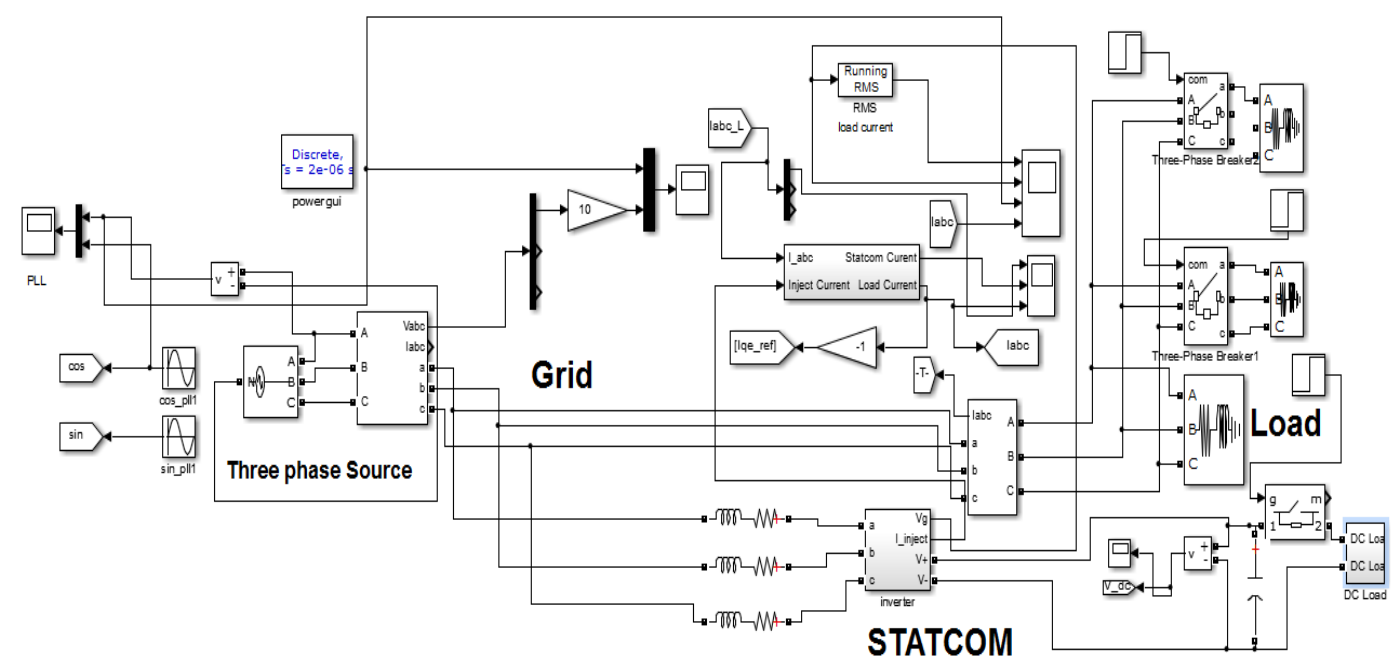

Fig.5 Simulation Model in MATLAB/SIMULINK

In fig 5, it shows the overall simulation diagram of the proposed hysteresis current control of STATCOM. The standard three phase source of $440 \mathrm{~V}$ is used here. The factor which decides the rating of grid is depending upon the rating of load. It should be 5 times that of load. The $1000 \mathrm{KVA}$ grid is considered in the system. The voltage sag of duration 0.5 


\title{
2 \\ ISSN (Print) : $2320-3765$ \\ International Journal of Advanced Research in Electrical, Electronics and Instrumentation Engineering
}

ISSN (Online): 2278 - 8875

\author{
(An ISO 3297: 2007 Certified Organization)
}

\section{Vol. 4, Issue 3, March 2015}

sec to $0.8 \mathrm{sec}$ is created in this scheme. In this scheme three phase RL load is connected to the grid, another three phase RL load of same rating is connected to the grid with the help of circuit breaker. In this work STATCOM Voltage Source Inverter (VSI) is connected between the three phase source and the load. The voltage sag mitigation by using STATCOM in this scheme is used to attain the voltage stability. Here, Hysteresis current control method is used to generate pulses for VSI.

\section{SIMULATION RESULTS AND DISCUSSION}

Table.1 Comparison between the proposed method and existing method

\begin{tabular}{|l|l|l|}
\hline Parameters & $\begin{array}{l}\text { STATCOM using hysteresis } \\
\text { current controller }\end{array}$ & $\begin{array}{l}\text { STATCOM using space vector } \\
\text { modulation }\end{array}$ \\
\hline Voltage sag & $0.9 \mathrm{pu}$ & $0.85 \mathrm{pu}$ \\
\hline Statcom current & $17 \mathrm{Amps}$ & $10 \mathrm{Amps}$ \\
\hline Reactive power injected & $0.80 \mathrm{pu}$ & $0.74 \mathrm{pu}$ \\
\hline Time for mitigating voltage sag & $0.25 \mathrm{sec}$ & $0.3 \mathrm{sec}$ \\
\hline
\end{tabular}

In table 1, it shows the comparison between the proposed method and the existing method. The system has simulated using the proposed STATCOM with Hysteresis current controller.

In fig 6, it shows the source voltage is affected when other three phase load are suddenly connected.

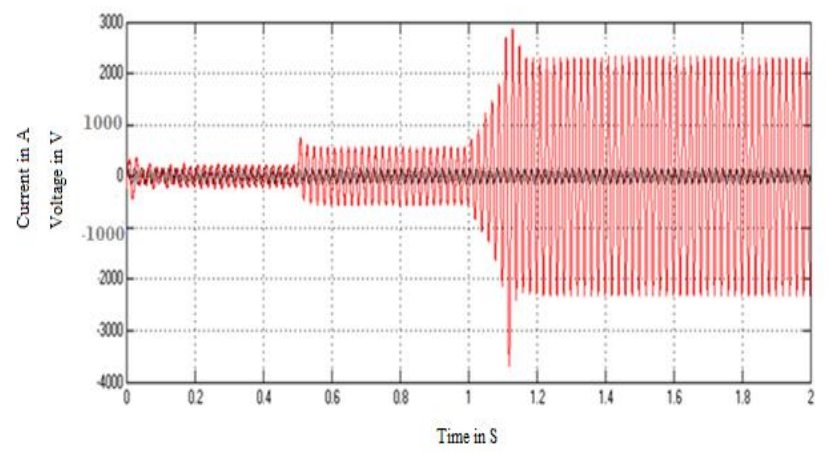

Fig. 6 Source Voltage and Current

In fig7, it shows the load current, STATCOM current and rms value of load current waveform. Till 0.5 sec only first load is there, after $0.5 \mathrm{sec}$ second load is connected so there is increase in load current. Up to 0.5 sec current value is 20 amps. When the second load is connected current value rises from 20 amps to 40 amps. During voltage reduction, STATCOM need to inject current into injected into the grid, hence the current value of STATCOM is negative. Load current increases when the second 3 phase RL load is connected. the grid. Current is injected into the grid hence the current value of STATCOM is negative. Load current increases when the second 3 phase RL load is connected. 


\section{International Journal of Advanced Research in Electrical, Electronics and Instrumentation Engineering}

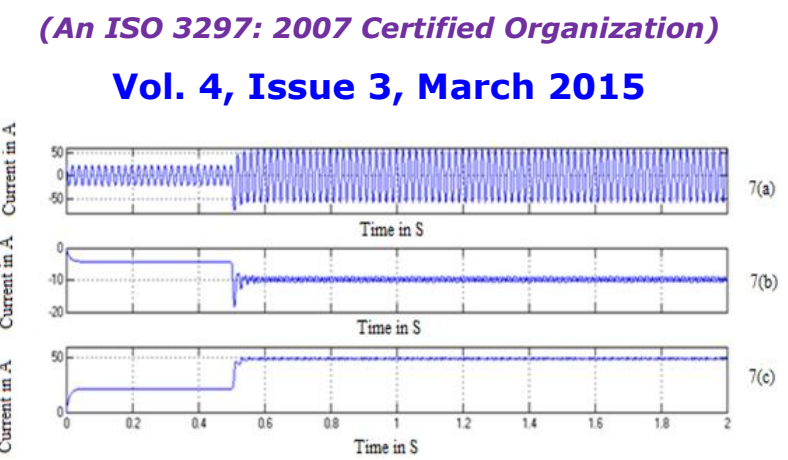

Fig. 7 (a) Load Current, 7(b) STATCOM Current and 7(c) Load Current RMS Value

In fig 8, it shows RMS value of voltage in the grid, voltage sag, reference voltage and load current. voltage sag in the grid due to connection of the another 3 phase RL load.Till $0.5 \mathrm{sec}$ grid voltage is same as that of source voltage .After the second 3 phase RL load is connected there is reduction in voltage i.e. Voltage sag, duration of voltage sag is 0.5 $\mathrm{sec}$ to $0.8 \mathrm{sec}$. At this moment STATCOM starts injecting current into the grid by the use of Hysteresis current controller to mitigate the voltage sag, and then we get a smooth sinusoidal voltage waveform. Up to 0.5 sec load current is 20 amps, when the other 3 phase RL load of same rating is connected then the load current increases.

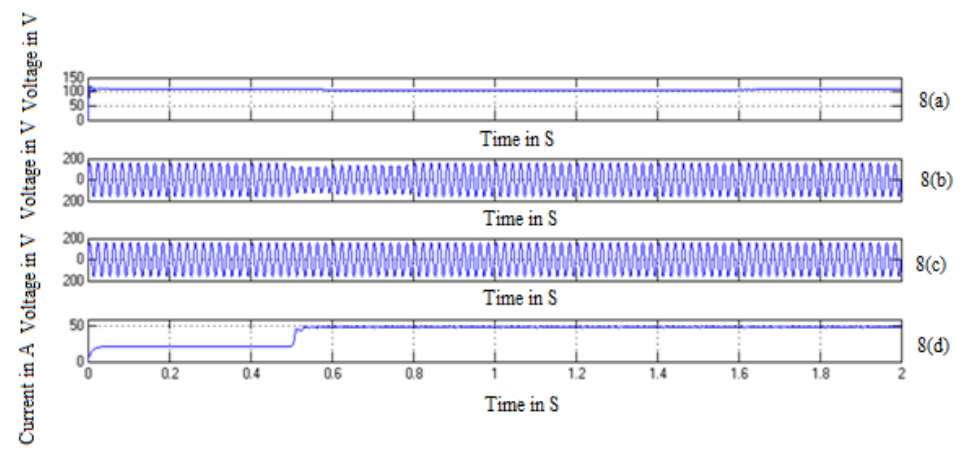

Fig. 8(a) RMS Voltage in Grid, 8(b)Voltage in Grid, 8(c) Reference Voltage, 8(d) Load Current

In fig 9, it shows the active and reactive power of the system. During first load, there is no big change in Real power and reactive power. First the real power is increased from 0.2 to $0.4 \mathrm{pu}$ and after $0.15 \mathrm{sec}$ it lowers to $0.3 \mathrm{pu}$ till $0.5 \mathrm{sec}$. After $0.5 \mathrm{sec}$ when the second load is connected then both real and reactive power is increased from $0.35 \mathrm{pu}$ to $0.9 \mathrm{pu}$ but the difference is very small between them because at that time STATCOM comes into action due to voltage sag.

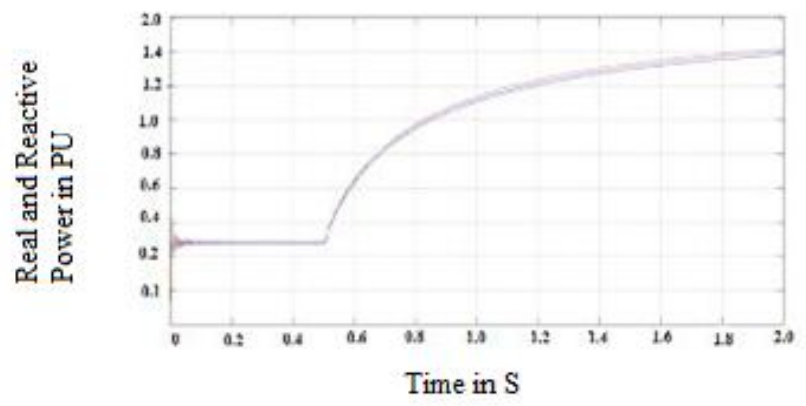

Fig. 9 Real power and Reactive power in the system 


\title{
(9) \\ International Journal of Advanced Research in Electrical, Electronics and Instrumentation Engineering
}

ISSN (Print) : $2320-3765$

ISSN (Online): $2278-8875$

\author{
(An ISO 3297: 2007 Certified Organization) \\ Vol. 4, Issue 3, March 2015
}

\section{VI.CONCLUSION}

A complete control scheme for STATCOM under Voltage sag has been presented in this paper. The objective of this work is to study the performance of STATCOM for mitigating voltage sag and to improve the quality of power to the end user. STATCOM using Hysteresis Current Controller has been investigated for voltage sag. It is clear from the simulation results that the STATCOM using Hysteresis current controller is simple and is generating the pulses for VSC by comparing the reference signal and carrier signal in terms of voltage. This work presents a STATCOM in distribution systems for compensation of voltage sag. The performance of proposed STATCOM with Hysteresis current controller has investigated through extensive simulation studies. From these studies it is observed that the proposed scheme completely compensated the voltage sag and supplies quality of power to the end - user.

\section{REFERENCES}

[1] AdriaJunyent-Ferr, OriolGomis-Bellmunt and Tim C. Green, "Current Control Reference Calculation Issues for the Operation of Renewable Source Grid Interface VSCs Under Unbalanced Voltage Sags”, IEEE Transactions on Power Electronics, Vol. 26, no. 12, pp. 3744-375, Dec. 2011.

[2] Antonio Camacho, Miguel Castilla and JaumeMiret, "Flexible Voltage Support Control for Three-Phase Distributed Generation Inverters Under Grid Fault", IEEE Transactions on Industrial Electronics, Vol. 60, no. 4, pp.1429-1441, Apr. 2013.

[3] N.Jelani and M.Molinas, "Stability investigation of control system for power electronic converter acting as load interface in AC distribution systems," in Proc.IEEE ISIE, pp.408-413, 2011.

[4] AhmetTeke, LütfüSaribulut and Mehmet Tümay, "A Novel Reference Signal Generation Method for Power-Quality Improvement of Unified Power-Quality Conditioner", IEEE Transactions on Power Delivery, Vol. 26, no. 4, pp.2205-2214, Nov. 2010.

[5] FarhadShahnia, ArindamGhosh, Gerard Ledwich and FiruzZare, "Voltage Unbalance Improvement in Low Voltage Residential Feeders with Rooftop PVs Using Custom Power Devices”, Elesvier Transactions on Electrical Power and Energy Systems 54, pp. 362-37, Apr. 2013.

[6] Fei Wang, Jorge L. Duarte and Marcel A. M. Hendrix, "Pliant Active and Reactive Power Control for Grid-Interactive Converters Under Unbalanced Voltage Dips", IEEE Transactions on Power Electronics, Vol. 26, no.5, pp.1511-1521, May. 2011.

[7] KamatchiKannan .V and N. Rengarajan, "Investigating the Performance of Photovoltaic based DSTATCOM using Icos $\Phi$ Algorithm", Elsevier, Electrical Power and Energy Systems 54, pp.376-386, Jan. 2014.

[8] KuangLi, Jinjun Liu, Zhaoan Wang and Biao Wei, "Strategies and Operating Point Optimization of STATCOM Control for Voltage Unbalance Mitigation in Three-Phase Three-Wire Systems", IEEE Transactions on Power Delivery, Vol. 22, no. 1, pp.413-422 , Jan. 2009.

[9] Miguel Castilla and JaumeMiret, "Modeling and Design of Voltage Support Control Schemes for Three-Phase Inverters Operating Under Unbalanced Grid Conditions", IEEE Transactions on Power Electronics, Vol. 29, no. 11, pp. 6139-6150, Nov. 2014.

[10] Padmanabh Thakur and Asheesh K. Singh, "Unbalance Voltage Sag Fault-Type Characterization Algorithm for Recorded Waveform", IEEE Transactions on Power Delivery, Vol. 28, no. 2, pp .1007-1014, Apr. 2013.

[11] Pedro Roncero-Sánchez, Enrique Acha, Jose Enrique Ortega-Calderon, Vicente Feliu, and Aurelio García-Cerrada, "A Versatile Control Scheme for a Dynamic Voltage Restorer for Power-Quality Improvement”, ,IEEE Transactions on Power Delivery, Vol. 28, no. 2, pp .277-284, Apr. 2009.

[12] Sabha Raj Arya,andBhim Singh, "Power Quality Improvement under Nonideal AC Mains in Distribution System”, Electric Power Systems Research 106, pp.86-94,May. 2014.

[13] SandeepAnand, B. G. Fernandes, and Kishore Chatterjee, "DC Voltage Controller for Asymmetric-Twin-Converter-Topology-Based HighPower STATCOM", IEEE Transactions on Industrial Electronics, Vol. 60, no. 1, pp.11-19 ,Jan. 2013.

[14] Tzung-Lin Lee, Shang-Hung Hu, and Yu-Hung Chan, "D-STATCOM with Positive Sequence Admittance and Negative-Sequence Conductance to Mitigate Voltage Fluctuations in High-Level Penetration of Distributed-Generation Systems", IEEE Transactions on Industrial Electronics, Vol. 60, no. 4, pp. 1417-1428, Apr. 2013. 